\title{
A proposal for a behavioral pre-consultation: Analysis of the use of a protocol during consultations
}

\author{
Proposta de pré-consulta comportamental: análise \\ de uso do protocolo durante consultas
}

\author{
Marina KOHLSDORF ${ }^{1}$ \\ Áderson Luiz COSTA JUNIOR ${ }^{1}$
}

\begin{abstract}
This study aimed to analyze how physicians, caregivers, and children use protocols regarding estimated issues to medical visits, procedure named pre-consultation lists, along treatment for childhood cancer. Three pediatricians and 24 dyads child-caregiver took part; each pair was interviewed before medical visits in order to report doubts, needs and issues estimated to the consultation. This list was attached to child's medical record as a memo of themes to discuss in the next medical visit. Results show that two physicians included effectively this file in their consultations and discussed a great amount of issues listed by caregivers and patients. Children did not refer to the listed issues, but parents, in smaller amounts, discussed the themes in the protocol. This procedure contributed to insert the child in consultations and it may facilitate the focus on specific themes, however the physician's main role in managing communication during pediatric medical visits is highlighted.
\end{abstract}

Keywords: Child health; Health communication; Neoplasms.

\section{Resumo}

Constitui objetivo deste trabalho analisar a maneira como médicos, cuidadores e crianças utilizam protocolos de estimativas de assuntos para discussão, procedimento denominado pré-consulta comportamental, durante atendimentos em onco-hematologia pediátrica. Participaram da pesquisa três pediatras e 24 díades criança-cuidador; cada dupla foi entrevistada antes de consultas para registrar dúvidas, demandas e assuntos estimados para o atendimento. Essa lista era anexada ao prontuário como um lembrete de temas para discussão na consulta em seguida. Os resultados mostraram que dois médicos incluíram efetivamente esse protocolo em seus atendimentos e discutiram grande parte dos assuntos indicados por cuidadores e pacientes. As crianças não fizeram referência aos assuntos listados, mas os pais, em menores proporções, discutiram as questões do protocolo. O procedimento contribuiu para maior inserção da criança nas consultas e pode facilitar o enfoque de temas específicos. Porém, destaca-se a primazia do médico em administrar a comunicação durante as consultas pediátricas.

Palavras-chave: Saúde da criança; Comunicação em saúde; Neoplasias.

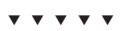

${ }^{1}$ Universidade de Brasília, Instituto de Psicologia, Laboratório de Desenvolvimento em Condições Adversas. Campus Darcy Ribeiro, s/n., Asa Norte, 79910-900, Brasília, DF, Brasil. Correspondência para/Correspondence to: M. KOHLSDORF. E-mail: <marinak@unb.br>.

Article based on the doctoral dissertation of M. KOHLSDORF, intitled: "Proposta de pré-consulta comportamental: análise da comunicação médico-cuidador-paciente em onco-hematologia pediátrica”. Universidade de Brasília, 2012. 
The quality of pediatric care has improved remarkably in recent decades, considering investments in primary healthcare, improved diagnosis and treatment techniques, intensified preventive programs, pre-, peri-, and postnatal care, and an increased number of public policies to control morbidity and mortality among children and adolescents (Patenaude \& Last, 2001; Silva, 2000; Tates \& Meeuwesen, 2001). This context has enabled a significantly higher percentage of cures and/or the control of previously fatal diseases such as pediatric cancer, and shows the importance of understanding how patients and their families experience the heath-disease continuum. One of the best times to grasp this understanding is the analysis of communication that takes place during pediatric visits, because consultations represent an essential context for the promotion of child development and enable stakeholders to address issues such as care, protection and psychosocial factors, including parental upbringing, school practices, feeding practices, family dynamics and socialization, which are also determinants of health and disease (Patenaude \& Last, 2001; Silva, 2000; Tates \& Meeuwesen, 2001).

The literature emphasizes that the quality of information provided by physicians is directly related to the satisfaction of patients with the service, general quality of health, adherence to treatment, symptoms and clinical responses, understanding concerning the diagnosis and treatment, improved management of psychosocial factors related to the treatment (e.g. satisfaction with sociofamilial support, dealing with professional and financial difficulties, adjustment to changes in the family routine and dynamics, parental upbringing practices), improved recall of explanations and decreased need to return to the outpatient clinic (Ammentorp, Kofoed, \& Laulund, 2011; Clark et al., 2000; Cohen \& Wambolt, 2000; Coyne \& Gallagher, 2011; Croom et al., 2011; Crossley \& Davies, 2005; DiMatteo, 2004; Drotar, 2009; Fiks, Localio, Alessandrini, Asch, \& Guevara, 2010; Fisher \& Broome, 2011; Howells \& Lopez, 2008; Nobile \& Drotar, 2003; Sleath et al., 2011; 2012; Swedlund,

222 Schumacher, Young, \& Cox, 2012).
Considering pediatric visits from a systemic perspective, it is worth noting that efficacious communication also impacts the experience of the professionals involved in the process because it implies the patients trust the physician, more and better information is provided by the pediatricians, psychosocial difficulties are alleviated (e.g., less frequent return medical visits, and a consequent decrease in work overload for medical staff, more efficient consultations, and greater ease in establishing diagnoses and prescribing treatments), improved understanding and recall of recommendations, (Crossley \& Davies, 2005; DiMatteo, 2004; Drotar, 2009; Howells \& Lopez, 2008; Nobile \& Drotar, 2003).

Another important aspect is that the literature shows that a pediatric consultation is administered by the physician responsible for most of the interactions, that is, the caregivers' participation in communication is between 38 and $48 \%$ and the child's participation in this verbal exchange is between 2 to $14 \%$, only providing basic information or establishing bonds with the professional; parents and physicians may exclude the patient due to a protective tendency (Coyne \& Gallagher, 2011; Coyne \& Harder, 2011; Hallström, 2004; Nova, Vegni, \& Moja, 2005; Perosa, Gabarra, Bossolan, Ranzani, \& Pereira, 2006; Ranzani, 2009; Tates, Elbers, Meeuwesen, \& Bensing, 2002a; Tates \& Meeuwesen, 2000; 2001; Tates, Meeuwesen, Bensing, \& Elbers, 2002b; Vaknin \& Zisk-Rony, 2010; Wassmer et al., 2004; Young et al., 2010; 2011).

There is also a discussion concerning individual demands of both caregivers and children, an aspect considered essential for satisfactory interactions (Aburn \& Gott, 2011; Coyne \& Gallagher, 2011; Coyne \& Harder, 2011; Lambert, Glacken, \& McCarron, 2011; Nestel, Taylor, \& Spender, 2004; Ranzani, 2009; Ringnér, Jansson, \& Graneheim, 2010; Zwaanswijk et al., 2011). Studies conducted by Felt and O'Connor (2003), Hayutin, Reed-Knight, Blount, Lewis, and McCormick (2009), and Silva (2000) report the effects of procedures estimating issues that will be addressed during communication with the pediatrician based on questionnaires and checklists that are completed by the caregivers and/or pediatricians before a consultation and are used as a reminder during 
consultations. In these studies, these procedures led individuals to more frequently address psychosocial topics, such as parental practices, school activities, difficulties related to family dynamics and routines, professional or financial hardships, in addition to greater scores for satisfaction on the part of caregivers and a greater focus on parents' specific demands, emphasizing the benefits of this type of intervention on the triadic interaction among the patient, caregiver and physician (Felt \& $\mathrm{O}^{\prime}$ Connor, 2003; Hayutin et al., 2009; Silva, 2000).

Even though studies addressing communication in the field of pediatrics are relevant, there is a scarcity of studies addressing psychosocial interventions designed to improve interactions, include the pediatric patient and promote individualized discussions concerning the demands of children and caregivers (Kohlsdorf, 2012). Additionally, the following aspects appear to be relevant: (a) direct observation of medical visits to promote reliability and understand the dynamics of the triadic interaction, avoiding indirect assessment of the communication process or measures that require recall or memory exercises such as interviews performed some time after the visit, and (b) studies assessing how caregivers, children and pediatricians use lists of topics to be addressed during the medical visit according to the aforementioned procedures, since this understanding may support future research.

This study is part of a larger research project addressing the effects of a procedure estimating topics to be discussed during medical visits, called behavioral pre-consultation, on pediatric consultations. Its specific objective was to present how this checklist was included in the consultations and its effective use by the physician-caregiverpatient triad. Other results of this larger research project can be found in different papers or by contacting the authors.

\section{Method}

\section{Participants}

Three physicians from the Pediatric Oncology-Hematology Center in the Federal District,
Brazil, denoted as P1, P2, and P3, aged between 34 and 49 years old and working in the field

Table 1

Characteristics of the dyads

\begin{tabular}{|c|c|}
\hline Characteristics of the dyads & Frequency \\
\hline \multicolumn{2}{|l|}{ Children's ages } \\
\hline 4 to 6 years old (incomplete) & 6 \\
\hline 6 to 8 years old (incomplete) & 5 \\
\hline 8 to 10 years old (incomplete) & 4 \\
\hline 10 to 12 years old & 9 \\
\hline Mean (Standard Deviation) & 8,2 years $(2,98)$ \\
\hline \multicolumn{2}{|l|}{ Children's education } \\
\hline Daycare or kindergarten & 8 \\
\hline $1^{\text {st }}$ to $3^{\text {rd }}$ grade & 9 \\
\hline $4^{\text {th }}$ grade on & 7 \\
\hline \multicolumn{2}{|l|}{ Time of treatment } \\
\hline Up to 1 month & 9 \\
\hline Between 1 and 2 months & 9 \\
\hline Between 2 and 4 months & 3 \\
\hline Between 4 and 6 months & 3 \\
\hline Mean (Standard Deviation) & 1,8 month $(1,53)$ \\
\hline \multicolumn{2}{|l|}{ Caregivers' kinship } \\
\hline Mothers & 22 \\
\hline Fathers & 2 \\
\hline \multicolumn{2}{|l|}{ Caregivers' ages } \\
\hline Up to 30 years old & 5 \\
\hline From 31 to 40 years old & 16 \\
\hline 41 years old and older & 3 \\
\hline Mean (Standard Deviation) & $35,6(7,25)$ \\
\hline \multicolumn{2}{|l|}{ Caregivers' education } \\
\hline Elementary school up to $4^{\text {th }}$ grade & 4 \\
\hline Middle School up to $8^{\text {th }}$ grade & 7 \\
\hline High School & 9 \\
\hline College & 4 \\
\hline \multicolumn{2}{|l|}{ Caregivers' marital status } \\
\hline Married/stable union & 16 \\
\hline Single & 4 \\
\hline Divorced/widowed & 4 \\
\hline \multicolumn{2}{|l|}{ Origin } \\
\hline Distrito Federal & 18 \\
\hline Other states (BA, GO, MG, MT, RR) & 6 \\
\hline \multicolumn{2}{|l|}{ Siblings of the child under treatment } \\
\hline Single child & 3 \\
\hline 1 or 2 siblings & 16 \\
\hline More than 2 siblings & 5 \\
\hline \multicolumn{2}{|l|}{ Family monthly income } \\
\hline Less than 1 times the minimum wage & 6 \\
\hline Between 1 and 4 times the minimum wage & 19 \\
\hline More than 4 times the minimum wage & 1 \\
\hline
\end{tabular}

Note: BA: Bahia; GO: Goiás; MG: Minas Gerais; MT: Mato Grosso; RR: Roraima. 
between 7 and 26 years, participated in this study. Additionally, 27 child-caregiver dyads receiving pediatric cancer treatment were invited to participate in the study, but three refused to participate. Table 1 presents the socio-demographic data of the 24 dyads that agreed to participate in the study.

\section{Instruments}

An observation sheet specifically developed for this study was used. It was completed manually over the course of the medical visits to record observations concerning the communication behavior among the physicians, caregivers and children during routine visits and complementary elements to contextualize the care provided. The purpose of this form was to record behavior functionally relevant to the communicative interaction, aspects related to the context of care, and other information that could later enhance data analysis; e.g., when some of the participants left the physician's office, the child's or caregiver's crying episodes, or when the physicians read the preconsultation list described below.

A protocol for behavioral pre-consultation records based on the studies conducted by Zannon (2001) and Zannon, Pereira, Arruda, Kohlsdorf, \& Rocha (2002) was used (Attached). This protocol described both the patient and caregiver: (a) diagnosis definition; (b) understanding regarding therapeutic planning; (c) difficulties concerning the treatment; (d) costs to adhere to treatment; (e) doubts and expectations; ( $f$ ) issues expected to be discussed in the ensuing consultation, and (g) other issues. To address these topics, a semi-structured script was developed for the pre-visit interview.

\section{Procedures}

The physicians and caregivers were invited to participate in the study and read and signed free and informed consent forms, while the children consented verbally in the presence of their parents.

The procedure consisted of brief meetings 224 with each dyad at the time they were waiting for the medical consultation in the waiting room. The participants were interviewed before the consultation for an average of $17 \mathrm{~min} 2 \mathrm{~s}$ (Standard Deviation - $S D=6.34$ ); interviews lasted a minimum of $5 \mathrm{~min} 55 \mathrm{~s}$ and a maximum of $35 \mathrm{~min} 25 \mathrm{~s}$. At this point, the demands and topics suggested by parents and children were recorded in the pre-consultation protocol, a document that was attached to the cover of the patient's medical file that would be used at the subsequent consultation. The document served as an indicator to the physicians of the dyad's understanding regarding the diagnosis and treatment, difficulties, doubts, issues they expected would be addressed during their visit, and other relevant aspects. At the beginning of data collection, each physician was verbally instructed in regard to the purpose of this protocol:

\begin{abstract}
We will interview patients and caregivers before the consultation and record their demands on this sheet, which will be attached to the cover of the patients files to be included in the following consultation as a reminder of the listed topics.
\end{abstract}

A total of 70 consultations were audiorecorded with the three Physicians $(P)$ because 15 dyads attended more than one consultation. Twenty-three consultations were recorded with P1, 33 with $\mathrm{P} 2$, and 14 consultations with P3. The duration of consultations ranged from $9 \mathrm{~min} 14 \mathrm{~s}$ to $41 \mathrm{~min} 24 \mathrm{~s}$, with an average of $21 \mathrm{~min} 2 \mathrm{~s}(S D=7.40)$.

In accordance with Resolution no 196/96, Ministry of Health, the research project was submitted to and approved by the Fundação de Ensino e Pesquisa em Ciências da Saúde da Secretaria on October $5^{\text {th }}, 2009$ (Protocol $n^{\circ} 301 / 09$, Referee report $n^{\circ} 289 / 2009$ ).

\section{Results}

Figure 1 presents the correspondence between topics recorded in the pre-consultation protocol and their inclusion in the communication of consultations, chronologically organized, considering only the interaction between physicians and children. In this first analysis, we considered the initiative of addressing the topics listed, that is, 
P1
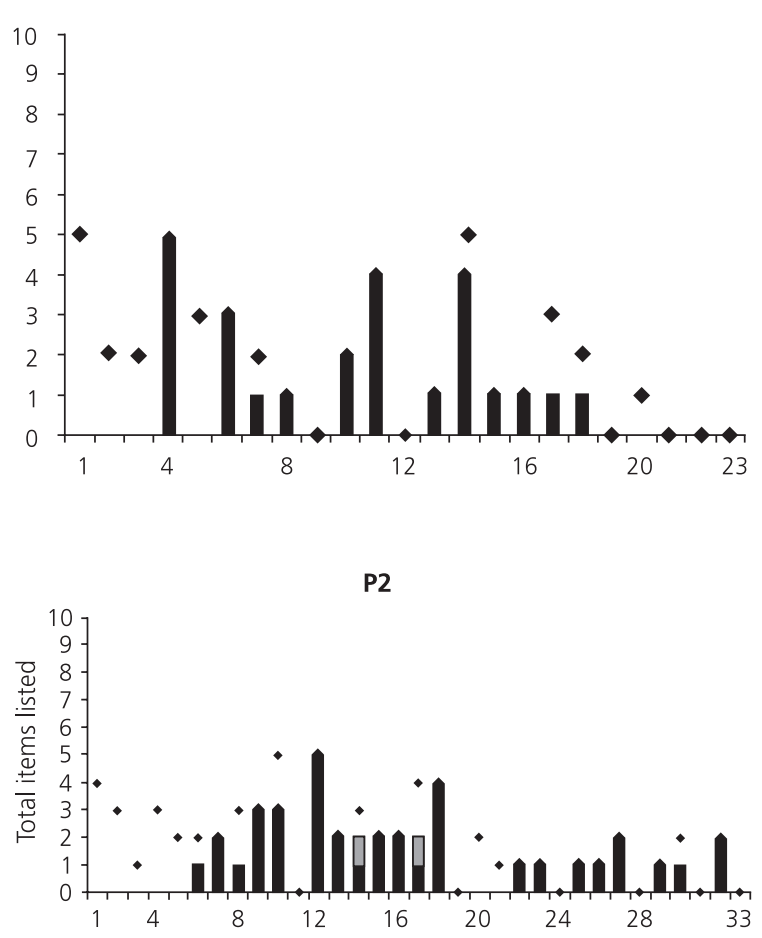

P3

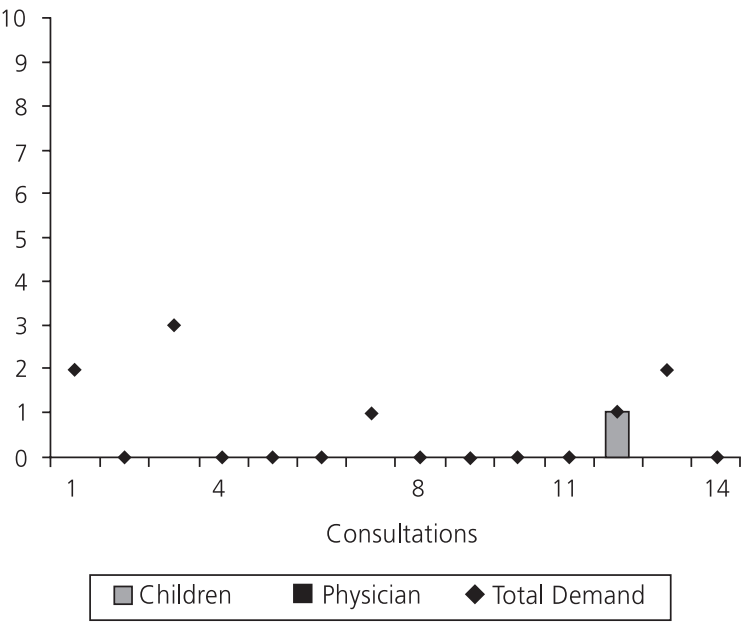

Figure 1. Initiative of children to address items listed in the pre-consultation.

which individual in the triad first mentioned the topic previously recorded in the protocol. We observed whether there was a correspondence between listed items and verbalizations.

Therefore, for this analysis, presented in Figure 1, we considered the total amount of items listed in each pre-consultation (indicated as "total demands") and, within these total amounts, the absolute frequency of items first addressed by the physicians (e.g., physician reads the pre-consultation protocol and says: "do you want to know when you will be able to go back to school? Only by the end of the year, ok?") and the absolute frequency of topics initially addressed by the children (e.g. child asks: "can I already go back to school ma'am?", which corresponds to a demand previously noted in the pre-consultation).

Note that there were only three times the children initiated addressing items that were previously listed in the protocol. These initiatives correspond to only $2 \%$ of total demands. P1 and P2 showed a remarkable pattern of discussing the items listed in the protocol, even though these physicians did not address any of the items listed for 24 consultations.

Physicians 3 did not follow a pattern in regard to the protocol and mentioning the items listed. Specifically in regard to this physician, few demands were recorded, an aspect that may be related to the children's clinical condition (this physician provided care only to patients with solid tumors, a condition that causes frequent pain and sickness and may hinder communication during consultations) or to the duration of treatment (four months for all the patients). The only demand included in the communication was on the initiative of the child and was related to dietary restrictions ("can / eat strawberry yogurt?"). Items not included in the consultations provided by P3 were related to therapeutic planning $(n=2)$, difficulties with procedures $(n=2)$, diet $(n=2)$, issues concerning care, hygiene and leisure $(n=1)$, and school activity $(n=1)$.

In ten consultations, P1 failed to include at least one item in the consultation regarding: fundamentals of neoplasia $(n=6)$; difficulties regarding the treatment $(n=6)$; management of side effects $(n=2)$; recommendations of care, hygiene, and leisure $(n=2)$; therapeutic planning $(n=3)$. For the visits recorded with P2, all the items were addressed in 14 consultations and in 13 consultations there were demands that were not addressed and that were related to behavioral 
complaints or difficulties with the treatment ( $n=$ $8)$, fundamentals of neoplasia $(n=5)$, dietary recommendations $(n=4)$, orientation regard care or hygiene $(n=3)$, therapeutic planning $(n=4)$, or school activity $(n=1)$.

Considering the consultations of $\mathrm{P} 2$, we note that visits 3, 11, 17 and 20 were atypical because they were either for urgent care/hospitalization of the child and/or difficulties faced within the service. This context may potentially impact an effective inclusion of the pre-consultation in the communication, hindering the discussion of demands previously listed and may be related to low adherence rates for the use of the protocol in these specific cases.

Figure 1 also presents interesting data regarding the gradual inclusion of the preconsultation in pediatric communication because the consultations were presented in chronological order. Considering the consultations recorded with P1, the items listed were not addressed in the three first visits, however, after the fourth consultation, there is a remarkable change in the physician's behavioral pattern as this professional starts, though irregularly, to include the topics listed by the children. In the first five consultations provided by P2, topics listed were not addressed. However, it is noticeable that from the sixth consultation on, the discussion of items that interested the children began to be addressed.

Some examples that illustrate the initiative of including the items may be highlighted, such as the report "here doctor [child points out to the protocol] here is what I wanted to ask about school, when can I go back?" (dyad assisted by P2) or "you said here in the pre-consultation that you wanted to know when your hair would fal outl, right?" (P1) and also [physician read the pre-consultation protocol] "about the surgery, it'll probably happen in about two months, but it depends on how the tumor responds to this first cycle, you know" (P2).

Figure 2 presents the initiative of including the items on the part of caregivers or physicians, considering the correspondence between items listed in the pre-consultation protocol and their inclusion in the communication, based on analyzing the consultations in chronological order. Similar to
Figure 1, we considered the total amount of items listed in each pre-consultation (indicated as "total demands) and within these total amounts, the absolute frequency of items first addressed by the physicians (e.g. "the next hospitalization will be only next month, ok?") and absolute frequency of topics initially addressed by the caregivers (e.g., mother asks "how long will he take this medication?", which corresponded to a demand previously listed in the pre-consultation protocol.

We note that both $\mathrm{P} 1$ and $\mathrm{P} 2$ were usually the first to address the topics listed, however, the caregivers also had an important part in including the demands in the communication process, which corresponded to $30 \%$ of the total initiatives. Some of the items listed were not discussed by P1 in 18 consultations. These demands referred to parents' difficulties and/or expectations regarding the clinical response $(n=15)$, fundamentals of neoplasia $(n=5)$, information on relapses $(n=5)$, recommendations concerning care, hygiene and leisure $(n=5)$, management of side effects $(n=5)$, difficulties regarding the healthcare system $(n=2)$, and school activities $(n=1)$.

Considering the consultations of $\mathrm{P} 2$, demands not addressed during 12 consultations involved complaints in regard to the child's behavior $(n=9)$, management of symptoms or intercurrences $(n=6)$, fundamentals of neoplasia or treatment $(n=4)$, dietary recommendations $(n=3)$, orientation regarding care or hygiene $(n=2)$, therapeutic planning $(n=2)$, use of alternative medication $(n=1)$, and school activities $(n=1)$. According to what was previously indicated, consultations 3, 11, 17 and 20 were atypical either due to the child's clinical condition or difficulties faced within the healthcare service, which may explain the infrequent use of the protocol, or no use at, all during these consultations.

Again, we note the low adherence to the protocol on the part of P3, however, when the physician did not address the items listed in the protocol, the caregivers took the initiative to address and discuss these items, which corresponded to $84 \%$ of the total initiated discussions. The topics included by P3 were therapeutic planning, 


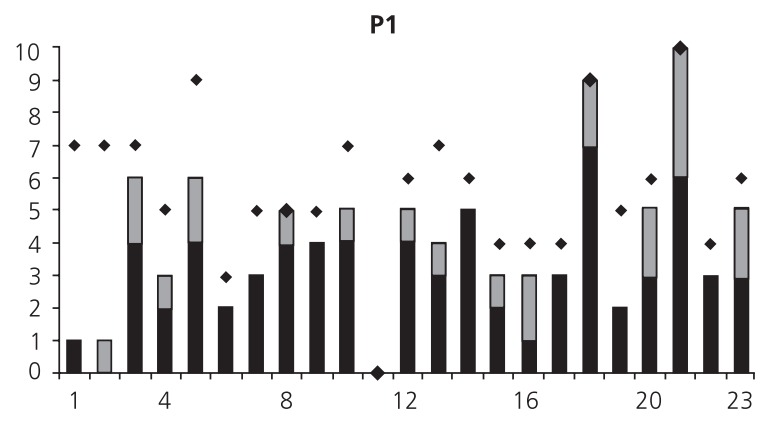

P2

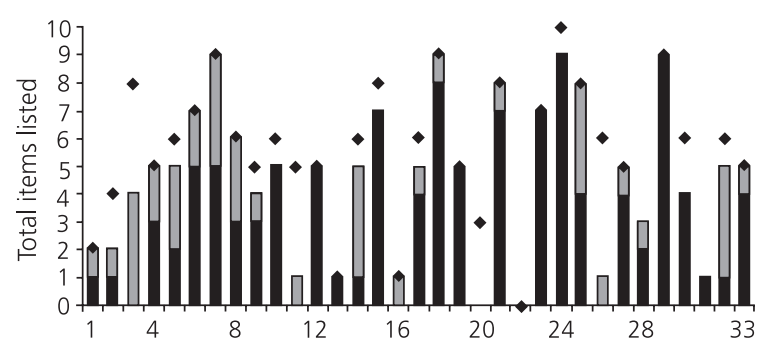

P3

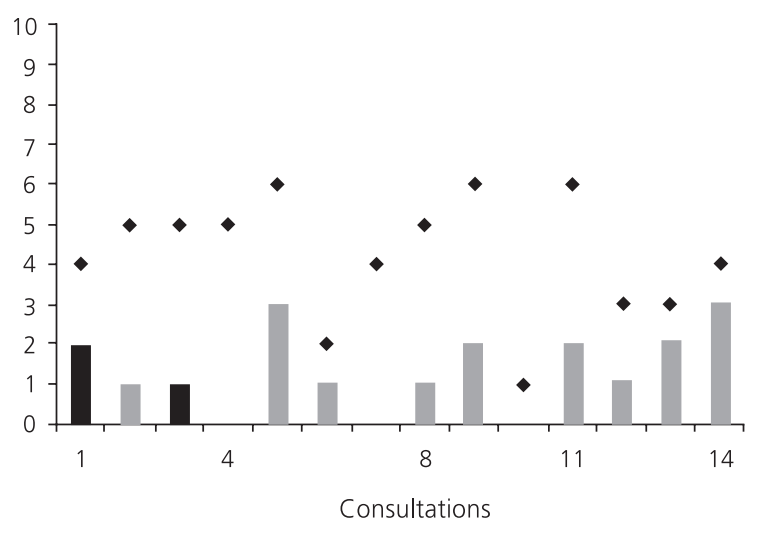

$\square$ Caregiver $\quad$ Physician Total Demand

Figure 2. Initiative in addressing items listed by the caregivers in the pre-consultation protocol.

recommendations regarding care, hygiene or leisure, use of alternative medication and traditional medication (Bactrim). In all the consultations, there were items not addressed that corresponded to parental upbringing difficulties and/or expectations regarding clinical response $(n=9)$, recommendations regarding care, hygiene and leisure $(n=6)$, therapeutic planning and hospitalization $(n=6)$, fundamentals of neoplasia or treatment $(n=5)$, management of intercurrences or side effects $(n=3)$, use of medication $(n=3)$, concern regarding relapses or sequelae $(n=3)$, dietary recommendations $(n=3)$, and doubts concerning exams $(n=1)$.

Figure 2 presents the gradual process by which the pre-consultation protocol was included in the consultations: virtually none of the items were addressed in the first consultations recorded with P1. However, from the third consultation on, the physician, even though irregularly, started addressing the items listed. P2 addressed the items in the protocol from the first consultation, and P3 used the pre-consultation protocol in the first and third visits only.

For a second data analysis, taking into account the process of adherence to the preconsultation protocol, the physicians' behavior (addressing the topics listed in consultations) was computed in terms of a percentage. Hence, only the behavior of the pediatricians was considered and the parents' or patients' verbalizations were excluded. We consider the physicians to have adhered to the protocol when we could observe total correspondence between the items listed and those addressed by the physicians, even when a child or caregiver had brought it up earlier in the consultation. In this analysis, the examples include [physician reads the protocol and checks each item] "we've already talked about school... hospitalization, ok... medication is alright... We've discussed everything, right?", (P2); "it's written here that you want to know the cause of the tumor, but we don't know, nobody knows, so don't think or dwell on that, ok", (P1); and also "about the medication, what you've already asked and is listed here, do you have any additional doubts?" (P1). This result shows a process in which the routine of the consultations changed, gradually including the protocol in the communication process. Figure 3 shows this curve of acquisition of behavior concerning the inclusion of the topics listed and considering the chronological order of consultations.

Figure 3 shows the procedural acquisition, by $\mathrm{P} 1$ and $\mathrm{P} 2$, of behavior concerning the inclusion of the pre-consultation protocol in the consultations, taking into account both the demands of the 
caregivers and children. Considering the consultations recorded with $\mathrm{P} 1$, we note this professional's low adherence to the protocol in the first two visits; however from the third and fourth consultations, P1 established a regular pattern, from 40 to $100 \%$, of the effective use of the protocol. Consultations 1, 5 and 19 were considered atypical because the children required urgent hospitalization (consultations 1 and 19) and there were issues within the service that required P1 to constantly leave the office (consultation 5). These contexts potentially influenced the extent of adherence to the protocol in these specific consultations and hindered addressing the items listed due to other priorities within the service.

Taking into account the consultations recorded with $\mathrm{P} 2$, we stress that the demands of caregivers began being addressed more regularly after the fourth session. The demands of children, however, were included in an irregular fashion and only after the sixth consultation. These findings also show a procedural acquisition of behavior on the part of the physician to address the items listed during consultations. Consultations 3, 11, 17 and 20 were atypical due to the clinical conditions of the children and difficulties in providing the service, an aspect that potentially influenced the low adherence to the protocol in these specific events.

As previously noted, P3 showed low adherence to the protocol, addressing $50 \%$ of the items listed by the caregiver in the first consultation and $20 \%$ of the caregiver's items in the third consultation, as well as $33 \%$ of the child's demands in the third consultation. Nonetheless, P3 stopped using the pre-consultation protocol in the remaining consultations. At the end of the study, in an interview, the physician listed the reasons for not adhering to the protocol, which included difficulties faced within the service:

I confess that $r d$ read it at the beginning but then, because of the rush, I no longer had time to read it. What makes it difficult is the amount of patients. It is the same with the medical files, with all these patients, you don't have time to check the medical file and the pre-consultation protocol is another 228
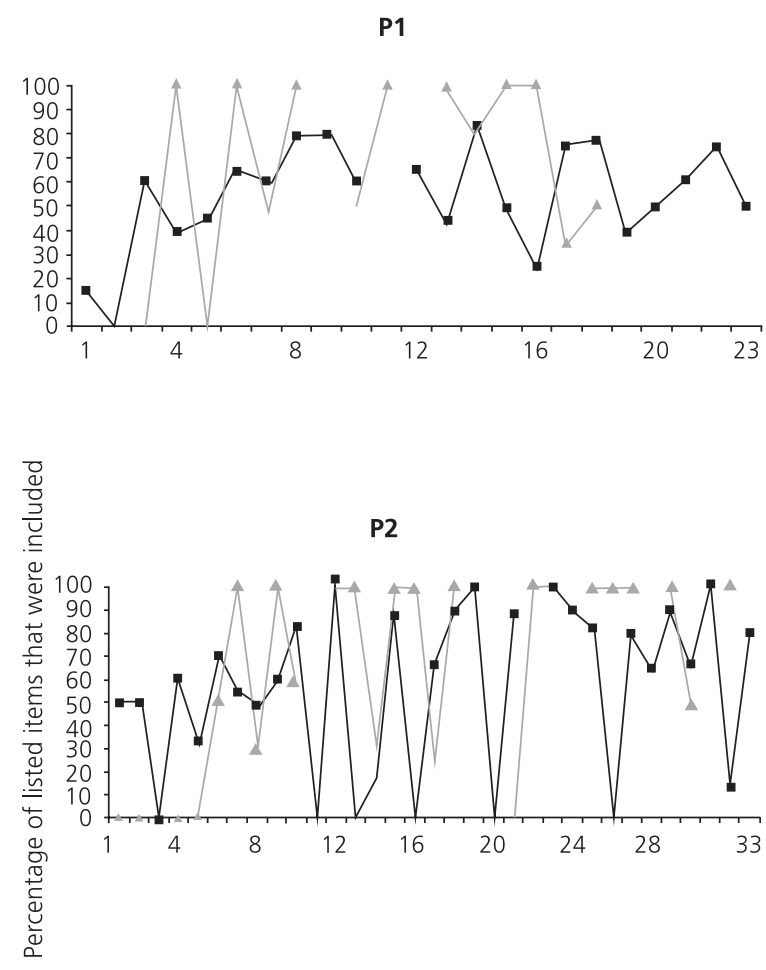

P3

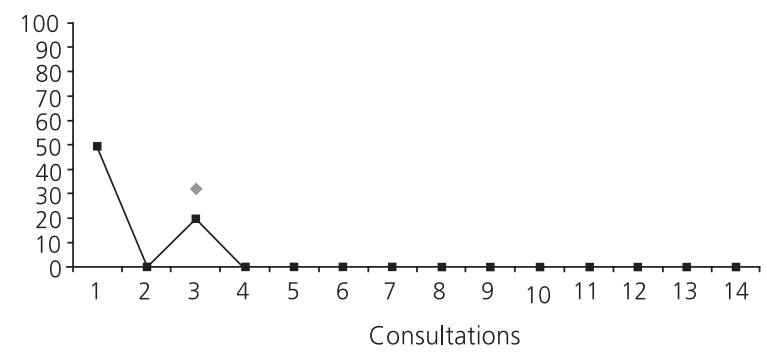

$\leadsto$ Children's demands $\rightarrow-$ Caregiver's demands

Figure 3. Percentage of items listed and addressed by the physicians during consultations.

\section{Discussion}

This paper presents an analysis concerning the inclusion of topics listed in a pre-consultation protocol to be addressed during pediatric consultations. It is part of a larger study addressing the effects of pre-consultation protocols on interaction during consultations. The results present important information for future research and interventions in the context of pediatric care, which we discuss below. 
First, we stress that children have little participation in the discussion of the topics listed: children's participation corresponds to only $2 \%$ of the initiated discussions of the items listed. This finding corroborates data in the literature regarding the exclusion of pediatric patients from communication during medical visits (Coyne \& Gallagher, 2011; Coyne \& Harder, 2011; Hallström, 2004; Nova et al., 2005; Perosa et al., 2006; Ranzani, 2009; Tates et al., 2002a; 2002b; Tates \& Meeuwesen, 2000; Vaknin \& Zisk-Rony, 2010; Wassmer et al., 2004; Young et al., 2010; 2011). It is, however, important to note that the effective use of the pre-consultation protocol on the part of P1 and P2 contributed to including specific issues listed by the children in communication, increasing the participation of pediatric patients in the communication process, an aspect emphasized as being relevant in healthcare delivery (Aburn \& Gott, 2011; Coyne \& Gallagher, 2011; Coyne \& Harder, 2011; Lambert et al., 2011; Nestel et al., 2004; Ranzani, 2009; Ringnér et al., 2010; Zwaanswijk et al., 2011).

Therefore, this study's results present an important initiative to include children in the communication within consultations, contributing to changing the physician-patient relationship to achieve more equalitarian, cooperative and humanized standards. In other words, asking the child to report doubts and suggest topics to be discussed during consultations may be a way to sensitize pediatricians to the need to focus communication on the patients' individual demands, considering them to be the main actors in their health-disease continuum, and who, therefore, should have an active role during consultations. Additionally, enabling the child to reflect upon his/ her own demands during the pre-consultation interview may encourage pediatric patients to practice self-observation, which also contributes to a more participative and assertive role over the course of their treatment, and ultimately, promotes self-care and healthy behaviors in the future adult from a preventive perspective.

In summary, this study represents one of the first initiatives reported in the Brazilian literature concerning interventions aimed to encourage children undergoing chronic treatment to participate in medical visits, and at the same time, favors a change in the communication patterns of physicians toward pediatric patients, contributing to change the traditional physician-patient relationship, moving toward a more biopsychosocial and humanized model. It is necessary to explore other ways pre-consultation protocols can be used, such as in playful interviews with children or implementing pre-consultation forms to be filled out at home.

These findings, combined with the analysis of the initiatives of caregivers in addressing the topics listed (corresponding to $30 \%$ of the initiatives), emphasize that the communication in medical consultations is centered on the physicians, an aspect already highlighted in other studies (Coyne \& Gallagher, 2011; Coyne \& Harder, 2011; Hallström, 2004; Tates et al., 2002a; Tates \& Meeuwesen, 2000; 2001; Tates et al. 2002b; Vaknin \& Zisk-Rony, 2010; Wassmer et al., 2004; Young et al., 2010; 2011). It is worth noting, however, that the caregivers assisted by P3, who did not follow the protocol, presented remarkable rates of including the topics listed in the consultations, which may be related to the encouragement and sensitization promoted in the pre-consultation and greater communication of demands on the part of the caregivers.

The topics that were not addressed by the physicians mainly reveal topics directly related to the treatment, such as fundamentals of neoplasia, therapeutic planning, and recommendations concerning care, and hygiene, among others. These findings do not allow us to infer whether the content or quality of the topics listed are related to the non-inclusion of these items in the consultation on the part of the physician; i.e., we cannot affirm whether there are topics that are more difficult for physicians to discuss with children and/or caregivers and, therefore, are avoided during consultations.

In agreement with the literature, preconsultation protocols listing topics to be discussed during consultations can improve communication (Felt \& O'Connor, 2003; Hayutin et al., 2009; Silva, 2000). It is also worth noting, however, that the 
inclusion of the protocol in the consultations on the part of the physicians showed a gradual change in their behavioral patterns in regard to the items listed. In some consultations, the inclusion of topics listed may be hindered by the patients' clinical conditions or difficulties faced by the physicians within the healthcare service. The latter is noted by P3 as an obstacle to the use of the protocol in the consultations.

One important limitation of this study is related to the small sample of physicians, caregivers and children. A larger group of participants would enable more homogeneous data on the effective use of pre-consultation protocols during consultations. Nonetheless, it is important to note that the physicians participating in this study corresponded to $50 \%$ of the population available for the study in the single public hospital providing care to children undergoing cancer treatment. Another limitation is the amount of consultations recorded with each physician. Likewise, a larger number of consultations would enable long-term prospective analyses. Finally, the consultations were only audio-recorded and observations were taken for complementary records, due to restrictions within the healthcare service. Video recordings would possibly enhance data analysis and reveal other important events concerning the use of a behavioral pre-consultation.

Further research is needed to systematize understanding of communication that takes place in pediatric contexts, including the perceptions of professionals regarding this interaction (Crossley \& Davies, 2005; DiMatteo, 2004; Drotar, 2009; Howells \& Lopez, 2008; Nobile \& Drotar, 2003). Additionally, it is important to investigate long-term effects of pre-consultation procedures on communication, and indirectly, on the patients' adaptation to treatment since the quality of an interaction is related to the satisfaction of patients, general quality of health, levels of adherence to care delivery, symptoms and clinical responses, understanding of the diagnosis and treatment, improved management of psychosocial factors explanations, and fewer outpatient return visits (Ammentorp et al., 2011; Clark et al., 2000; Cohen \& Wambolt, 2000; Coyne \& Gallagher, 2011; Croom et al., 2011; Crossley \& Davies, 2005; DiMatteo, 2004; Drotar, 2009; Fiks et al., 2010; Fisher \& Broome, 2011; Howells \& Lopez, 2008; Nobile \& Drotar, 2003; Sleath et al., 2011; 2012; Swedlund et al., 2012).

This study presented important findings concerning a process through which children, caregivers, and physicians can gradually include an intervention protocol in consultations and benefit from a simple measure related to improved pediatric communication. It is worth noting the gap in the literature concerning analyses of the process through which participants use certain interventions and adhere to such procedures, an extremely important discussion, as is data concerning how this intervention can change communication patterns. Hence, we highlight that this study provides important support to efforts to devise more efficient psychosocial interventions designed to test the effects of other types of interventions on the communication within the triad in healthcare contexts and contributes to the continuous improvement of healthcare provided to pediatric patients.

\section{References}

Aburn, G., \& Gott, M. (2011). Education given to parents of children newly diagnosed with acute lymphoblastic leukemia: A narrative review. Journal of Pediatric Oncology Nursing, 28(5), 300-305.

Ammentorp, J., Kofoed, P. E., \& Laulund, L. W. (2011). Impact of communication skills training on parents perceptions of care: Intervention study. Journal of Advanced Nursing 67(2), 394-400.

Clark, N. M., Gong, M., Schork, M. A., Kaciroti, N., Evans, D., Roloff, D., ... \& Mellins, R. B. (2000). Long-term effects of asthma education for physicians on patient satisfaction and use of health services. European Respiratory Journal, 16(1), 15-21.

Cohen, S. Y., \& Wamboldt, F. S. (2000). The parentphysician relationship in pediatric asthma care. Journal of Pediatric Psychology, 25(2), 69-77.

Coyne, I., \& Gallagher, P. (2011). Participation in communication and decision-making: Children and 
young people's experiences in a hospital setting. Journal of Clinical Nursing, 20, 2334-2343.

Coyne, I., \& Harder, M. (2011). Children's participation in decision-making: Balancing protection with shared decision-making using a situational perspective. Journal of Child Health Care, 15(4), 312-319.

Croom, A., Wiebe, D. J., Berg, C. A., Lindsay, R., Donaldson, D., Foster, C., ... Swinyard, M. T. (2011). Adolescent and parent perceptions of patient-centered communication while managing type 1 diabetes. Journal of Pediatric Psychology, 36(2), 206-215.

Crossley, J., \& Davies, H. (2005). Doctor's consultation with children and their parents: A model of competencies, outcomes and confounding influences. Medical Education, 39(8), 807-819.

DiMatteo, M. R. (2004). The role of effective communication with children and their families in fostering adherence to pediatric regimens. Patient Education and Counseling, 55(3), 339-344.

Drotar, D. (2009). Physician behavior in the care of pediatric chronic illness: Association with health outcomes and treatment adherence. Journal of Developmental \& Behavioral Pediatrics, 30(3), 246-254.

Felt, B. T., \& O'Connor, M. E. (2003). Use of the child development review increases residents' discussion of behavioral problems. Ambulatory Pediatrics, 3(1), 2-8.

Fiks, A. G., Localio, A. R., Alessandrini, E. A., Asch, D. A., \& Guevara, J. P. (2010). Shared decicion-making in pediatrics: A national perspective. Pediatrics, 126(2), 306-314.

Fisher, M. J., \& Broome, M. E. (2011). Parent-provider communication during hospitalization. Journal of Pediatric Nursing, 26, 58-69.

Hallström, I. (2004). Parents' and children's involvement in decision-making during hospitalization. Nursing Times Research, 9(4), 263-269.

Hayutin, L. G., Reed-Knight, B., Blount, R. L., Lewis, J., \& McCormick, M. L. (2009). Increasing parent-pediatrician communication about children's psychosocial problems. Journal of Pediatric Psychology, 34(10), 1155-1164.

Howells, R., \& Lopez, T. (2008). Better communication with children and parents. Paediatrics and Child Health, 18(8), 381-385.

Kohlsdorf, M. (2012). Proposta de pré-consulta comportamental: análise da comunicação médico-cuidador-paciente em onco-hematologia pediátrica (Tese de doutorado não-publicada). Universidade de Brasília.

Lambert, V., Glacken, M., \& McCarron, M. (2011). Communication between children and health professionals in a child hospital setting: A Child Transitional Communication Model. Journal of Advanced Nursing, 67(3), 569-582.
Nestel, D., Taylor, S., \& Spender, Q. (2004). Evaluation of an inter-professional workshop to develop a psychosocial assessment and child-centred communication training programme for paediatricians in training. BMCMedical Education, 4(25), 1-10.

Nobile, C., \& Drotar, D. (2003). Research on the quality of parent-provider communication in pediatric care: Implications and recommendations. Developmental and Behavioral Pediatrics, 24(4), 279-290.

Nova, C., Vegni, E., \& Moja, E. A. (2005). The physicianpatient-parent communication: A qualitative perspective on the child's contribution. Patient Education and Counseling, 58(3), 327-333.

Patenaude, A. F., \& Last, B. (2001). Cancer and children: Where are we coming from? Where are we going? Psycho-Oncology, 10(4), 281-283.

Perosa, G. B., Gabarra, L. M., Bossolan, R. P., Ranzani, P. M., \& Pereira, V. M. (2006). Aspectos psicológicos na comunicação médico-paciente no setting pediátrico. In M. A. Crepaldi, M. B. M. Linhares, \& G. B. Perosa (Orgs.), Temas em Psicologia Pediátrica (pp.57-82). São Paulo: Casa do Psicólogo.

Ranzani, P. M. (2009). O processo de comunicação médico/familiar/criança: a percepção de mães de crianças portadoras de doenças crônicas graves (Dissertação de mestrado não-publicada). Universidade Estadual Paulista Júlio de Mesquita Filho, Botucatu.

Ringnér, A., Jansson, L., \& Graneheim, U. H. (2010). Professional caregivers' perceptions of providing information to parents of children with cancer. Journal of Pediatric Oncology Nursing, 20(10), 1-9.

Silva, M. M. (2000). Consulta pediátrica: efeito de procedimentos instrucionais sobre os temas tratados (Tese de doutorado não-publicada). Universidade de Brasília.

Sleath, B., Ayala, G. X., Washington, D., Davis, S., Williams, D., Tudor, G., ... Gillette, C. (2011). Caregiver rating of provider participatory decision-making style and caregiver and child satisfaction with pediatric asthma visits. Patient Education and Counseling, 85, 286-289.

Sleath, B., Carpenter, D. M., Slota, C., Williams, D., Tudor, G., Yeatts, K., ... Ayala, G. X. (2012). Communication during pediatric asthma visits and self-reported asthma medication adherence. Pediatrics, 130(4), 1-7.

Swedlund, M. P., Schumacher, J. B., Young, H. N., \& Cox, E. D. (2012). Effect of communication style and physician-family relationships on satisfaction with pediatric chronic disease care. Health Communication, 27(5), 498-505.

Tates, K., \& Meeuwesen, L. (2000). "Let mum have her say": Turntaking in doctor-parent-child communication. Patient Education and Counseling, 40(2), 151-162.

Tates, K., \& Meeuwesen, L. (2001). Doctor-parent-child communication: A (re)view of the literature. Social Science and Medicine, 52(6), 839-851. 
Tates, K., Elbers, E., Meeuwesen, L., \& Bensing, J. (2002a). Doctor-parent-child relationships: A 'pas de trois'. Patient Education and Counseling, 48(1), 5-14.

Tates, K., Meeuwesen, L., Bensing, J., \& Elbers, E. (2002b). Joking or decision-making? Affective and instrumental behaviour in doctor-parent-child communication. Psychology and Health, 17(3), 281-295.

Vaknin, O., \& Zisk-Rony, R. Y. (2010). Including children in medical decisions and treatments: Perceptions and practices of healthcare providers. Child: Care, Health and Development, 37(4), 533-539.

Wassmer, E., Minnaar, G., Abdel Aal, N., Atkinson, M., Gupta, E., Yuen, S., \& Rylance, G. (2004). How do paediatricians communicate with children and parents? Acta Paediatrica, 93(11), 1501-1506.

Young, B., Ward, J., Salmon, P., Gravenhorst, K., Hill, J., \& Eden, T. (2010). Parents' accounts of the presence of their preadolescent child during discussions with doctors in the months after the child's diagnosis with serious illness: Qualitative interview study. Archives of Disease in Childhood, 95(1), 1230-1238.

Young, B., Ward, J., Salmon, P., Gravenhorst, K., Hill, J., \& Eden, T. (2011). Parents' experiences of their children's presence in discussions with physicians about leukemia. Pediatrics, 127(5), 1230-1238.

Zannon, C. M. L. C. (2001). Custo comportamental de um procedimento para prevenir não-adesão a tratamento pediátrico de doenças reumáticas: um tiro que saiu pela culatra (manuscrito não-publicado). Brasília: Universidade de Brasília.

Zannon, C. M. L. C., Pereira, R. M. G., Arruda, P. M., Kohlsdorf, M., \& Rocha L. E. P. (2002). Pré-consulta comportamental em reumatologia pediátrica: identificando problemas e promovendo aliança para o tratamento. Revista Brasileira de Reumatologia, 2002, 14-19, S79-S79.

Zwaanswijk, M., Tates, K., van Dulmen, S., Hoogerbrugge, P. M., Kamps, W. A., Beishuizen, A., \& Bensing, J. M. (2011). Communicating with child patients in pediatric oncology consultations: A vignette study on child patients', parents', and survivors' communication preferences. Psycho-Oncology, 20(3), 269-277.

Received: January 24, 2013

Final version: July 22, 2013

Approved: September 23, 2013

6) Estimated issues to the following consultation

232

7) Medication used: need receipt, medical reports? 